\title{
"A Clinical Study of Non Traumatic Acute Abdomen in Female Patients"
}

\author{
Dr. P Rama Rao ${ }^{1}$, Dr. G Raghuveer Chakravarthy ${ }^{2}$, Dr Shaik Sufiya ${ }^{2}$ \\ B Anil Kumar ${ }^{3}$, Dr. K.A.S.S.N.Kalyan ${ }^{3}$ \\ ${ }^{I}$ Associate Professor, General Surgery, Dr.Pinnamaneni Siddartha Institute Of Medical Sciences \& Research \\ Foundation, Chinaoutapalli, Krishna Dist, Andhra Pradesh, India. 2 \\ ${ }^{2}$ Assistant Professor, General Surgery, Dr.Pinnamaneni Siddartha Institute Of Medical Sciences \& Research \\ Foundation, Chinaoutapalli, Krishna Dist, Andhra Pradesh, India. \\ ${ }^{3}$ Junior Resident, General Surgery, Dr.Pinnamaneni Siddhartha Institute Of Medical Sciences \& Research \\ Foundation, Chinaoutapalli, Krishna Dist, Andhra Pradesh, India. \\ ${ }^{4}$ Professor, General Surgery, Dr.Pinnamaneni Siddartha Institute Of Medical Sciences \& Research Foundation, \\ Chinaoutapalli, Krishna Dist, Andhra Pradesh, India. \\ ${ }^{5}$ Junior Resident, General Surgery, Dr.Pinnamaneni Siddhartha Institute Of Medical Sciences \& Research \\ Foundation, Chinaoutapalli, Krishna Dist, Andhra Pradesh, India.
}

\begin{abstract}
:
Introduction: Acute abdominal pain is one of the most common presenting complaints at emergency of general surgery department and due to its varied aetiology it poses significant diagnostic challenges for surgeons, Acute abdomen is a term used to encompass a spectrum of surgical, medical and gynaecological conditions ranging from trivial to life threatening conditions, which require hospital admission, investigations and treatment.

Materials \& Methods: All Female patients with pain abdomen, attending OPD / admitted in a tertiary care Hospital, during the period from Sep 2014 to Oct 2016 about 100 patients were evaluated with clinical examination, ultrasonography and other necessary investigations, Results were made into charts based on different parameters and conclusions regarding commonest clinical entity, clinical symptom etc were drawn

Conclusion: Acute Appendicitis is the most common cause of acute abdominal pain of non traumatic origin in females presenting to surgeon Most Common age group in females that presented with Non traumatic Acute Abdomen was between 21-30 years. Most Consistent symptom was Pain abdomen followed by vomiting Most consistent Clinical sign was Abdominal tenderness, Most consistent Laboratory investigation was Leuckocytosis.

Keywords: Acute Abdomen, Appendicitis, Pain Abdomen, Ultrasonography
\end{abstract}

\section{Introduction}

Acute abdominal pain is one of the most common presenting complaints at emergency of general surgery department and due to its varied aetiology it poses significant diagnostic challenges for surgeons ${ }^{[I]}$

Acute abdomen is a term used to encompass a spectrum of surgical, medical and gynaecological conditions ranging from trivial to life threatening conditions, which require hospital admission, investigations and treatment.

It has sudden onset, can persist for several hours to days and is associated with wide variety of clinical features specific to underlying condition or disease.

It remains the important cause of mortality and morbidity in the emergency department.

Acute abdomen varies from mild dull aching pain, to frank guarding and rigidity with associated systemic symptoms.

Surgeon managing a case of acute abdomen should be aware of diverse etiology of acute abdomen, so there is a need to enlist the different etiologies leading to acute abdomen and the most common among them.

Women of childbearing age present a specific challenge when making decisions about diagnostic imaging. Gynaecological causes of abdominal pain are more common in these women, and radiation exposure should be avoided if pregnancy is likely. Therefore, abdominal or transvaginal ultrasonography is generally recommended for evaluating left lower quadrant pain in women of childbearing age ${ }^{[2]}$ and in pregnant patients with right lower quadrant abdominal pain. ${ }^{[3]}$

The investigative procedure involved should be such that, they should give a definite diagnosis in a short time. And after a diagnosis is made, the method of management of case holds prime importance.

Very often an accurate diagnosis cannot be made without surgery and many wonders are revealed on opening the abdomen. So it is the last court of appeal in investigating abdominal cases. 
This thesis endeavours to study the acute abdomen of nontraumatic origin in females .More importance was given to early diagnosis clinically, with simple investigation with blood, urine, plain X-ray studies and ultrasound examination of abdomen.

\section{Aims And Objectives}

\section{Materials And Methods}

1. To identify the spectrum of diseases causing non-traumatic acute abdomen in female patients.

2. To study the clinical features of various causes of non traumatic acute abdomen in female patients.

3. To diagnose by clinical and radiological examinations.

\section{Study Type:}

\section{Methodology}

This is a Prospective study conducted in Department of General Surgery at Dr. Pinnamaneni Siddhartha Institute of Medical Sciences \& Research Foundation which is a tertiary care centre teaching hospital during the period of September 2014 to October 2016

\section{Study Population:}

All female patients presenting with non traumatic acute abdominal pain

\section{Sampling design:}

Study subjects were selected as per inclusion and exclusion criteria by Consecutive sampling.

\section{Sample size:}

A total number of 100 patients were studies.

\section{Inclusion Criteria}

\section{Mode of Selection of Subjects:}

1. All female patients presenting with non traumatic acute abdominal pain.

2. Gynaecological and urological causes included

\section{Exclusion Criteria}

1. All male patients with both traumatic and non- traumatic acute abdominal pain.

2.Female Patients with blunt and penetrating trauma

3. Paediatric patients less than 18 yrs

\section{Study Variables}

a. Clinical History - Age, Symptoms - Pain Abdomen, Vomitings, Abdominal distension, Fever, Constipation, Urinary symptoms, Bleeding P/V, and Duration of Symptoms.

b. Physical Examination - Abdominal tenderness, Rebound tenderness, Guarding, Rigidity, Bowel sounds

c. Laboratory Investigations - Haemoglobin,Total WBC count.

d. Imaging Studies - X ray erect abdomen, USG Abdomen and Pelvis, CT scan when needed.

\section{Clinical History -}

A detailed history of complaints, assosciated symptoms along with the duration of the symptoms is meticulously taken and recorded in the case proforma.

\section{Physical Examination -}

a. General Survey: General condition of the patient is examined like Palor, Icterus, Cyanosis, Any signs of dehydration, Vital parameters etc. are recorded.

b. Local Examination of Abdomen: Done under standard headings of Inspection,

Palpation, Percussion, Auscultation and Per Rectal examination. Per Vaginal examination is done where necessary.Examination of other systems: All other systems examined clinically and evaluated where necessary for either fitness for surgery or for treating assosciated co morbidities 


\section{Results}

\section{Etiology of Acute Abdomen}

\begin{tabular}{|l|l|l|l|}
\hline S. No. & Causes & No. Of Cases & Percentage \\
\hline 1 & Acute Appendicitis & 23 & $23 \%$ \\
\hline 2 & Urological Causes & 22 & $22 \%$ \\
\hline 3 & Acute Cholecystitis & 17 & $17 \%$ \\
\hline 4 & Intestinal Obstruction & 14 & $14 \%$ \\
\hline 5 & Acute Pancreatitis & 11 & $11 \%$ \\
\hline 6 & Gynaecological causes & 8 & $8 \%$ \\
\hline 7 & Other causes & 5 & $5 \%$ \\
\hline & Total & 100 & \\
\hline
\end{tabular}

Out of 100 cases of abdominal conditions from November 2014 to October 2016, which were managed at Tertiary Care Hospital, the leading causes in abdomen were Acute appendicitis(23\%) followed by urological conditions $(22 \%)$.

\begin{tabular}{|l|l|l|l|l|l|l|}
\hline \multicolumn{2}{|l|}{ Age distribution of abdominal conditions } \\
\hline Age & $\begin{array}{l}\text { Acute } \\
\text { Appendicitis }\end{array}$ & $\begin{array}{l}\text { Acute } \\
\text { Cholecystitis }\end{array}$ & $\begin{array}{l}\text { Intestinal } \\
\text { Obstrction }\end{array}$ & $\begin{array}{l}\text { Urological } \\
\text { Causes }\end{array}$ & Others & Total \\
\hline $11-20$ & 4 & 1 & - & - & 2 & 7 \\
\hline $21-30$ & 13 & 3 & - & 8 & 7 & 31 \\
\hline $31-40$ & 6 & 3 & 2 & 8 & 5 & 24 \\
\hline $41-50$ & - & 5 & 3 & 1 & 6 & 15 \\
\hline $51-60$ & - & 1 & 3 & 3 & 3 & 10 \\
\hline $61-70$ & - & 3 & 4 & 2 & - & 9 \\
\hline $71-80$ & - & 1 & - & - & 1 & 2 \\
\hline $81-90$ & - & - & 2 & - & - & 2 \\
\hline Total & 23 & 17 & 14 & 22 & 24 & 100 \\
\hline
\end{tabular}

This table shows that majority of the patients are in the age group of 21-30 years and only 2 patients were above 81 years. Youngest patient in this group was 18 years and Eldest patient was 90 years old.

\section{Results Of Acute Appendicitis} Age distribution in acute appendicitis

Age distribution in acute appendicitis
\begin{tabular}{|l|l|}
\hline Age group & No. of cases \\
\hline $11-20$ & 4 \\
\hline $21-30$ & 13 \\
\hline $31-40$ & 6 \\
\hline $41-50$ & - \\
\hline $51-60$ & - \\
\hline $61-70$ & - \\
\hline $71-80$ & - \\
\hline $81-90$ & - \\
\hline Total & $\mathbf{2 3}$ \\
\hline
\end{tabular}

\begin{tabular}{|l|l|l|l|l|}
\hline & \multicolumn{1}{|c|}{ Symptoms in Acute Appendicitis } & \\
\hline & & & & \\
\hline S. No & Clinical Feature & No. of Patients & Percentage \\
\hline & & & & \\
\hline 1 & Abdominal Pain & 23 & & 100 \\
\hline & & & & \\
\hline 2 & Vomitings & 20 & & 87 \\
\hline & & & & \\
\hline 3 & Fever & 18 & 78 \\
\hline & & & & \\
\hline 4 & Diarrhoea & 3 & & 13 \\
\hline & & 11 & & 48 \\
\hline 5 & Constipation & & & \\
\hline & & - & & - \\
\hline 6 & Urinary Symptoms & & \\
\hline & &
\end{tabular}

Clinical signs presentation in Acute appendicitis

\begin{tabular}{|l|l|l|}
\hline Clinical Sign & No. of cases & Percentage \\
\hline RIF Tenderness & 23 & $100 \%$ \\
\hline Rebound tenderness & 15 & $65 \%$ \\
\hline Muscle guarding & 6 & $26 \%$ \\
\hline
\end{tabular}




\begin{tabular}{|l|l|l|}
\hline Mass in Right iliac fossa & 2 & $8 \%$ \\
\hline Rectal tenderness & 3 & $13 \%$ \\
\hline
\end{tabular}

Lab findings in acute appendicitis

\begin{tabular}{|l|l|l|}
\hline Lab finding & No. of patients & Percentage \\
\hline Leuckocytosis & 18 & $78 \%$ \\
\hline Shift of WBC to the left & 10 & $43 \%$ \\
\hline
\end{tabular}

\begin{tabular}{|l|l|l|l|}
\hline \multicolumn{2}{|c|}{ Results of urological cond } & \\
\hline S. no & Causes & No. of cases & Percentage \\
\hline 1 & UTI & 7 & 32 \\
\hline 2 & Ureteric Colic & 6 & 27 \\
\hline 3 & Pyelonephritis & 5 & 23 \\
\hline 4 & Renal Colic & 4 & 18 \\
\hline & Total & $\mathbf{2 2}$ & $\mathbf{1 0 0}$ \\
\hline
\end{tabular}

Age incidence of Urological Causes

\begin{tabular}{|l|l|}
\hline Age Group & No. of Patients \\
\hline $11-20$ & - \\
\hline $21-30$ & 8 \\
\hline $31-40$ & 8 \\
\hline $41-50$ & 1 \\
\hline $51-60$ & 3 \\
\hline $61-70$ & 2 \\
\hline $71-80$ & - \\
\hline $81-90$ & - \\
\hline
\end{tabular}

\begin{tabular}{|l|l|l|l|}
\hline \multicolumn{2}{|l|}{ Results of Acute Cholecystitis } & \\
\hline & & Age Incidence of Acute Cholecystitis \\
\hline & S. No & Age group & No. of Cases \\
\hline & 1 & $11-20$ & 1 \\
\hline & 2 & $21-30$ & 3 \\
\hline & 3 & $31-40$ & 3 \\
\hline & 4 & $41-50$ & 5 \\
\hline & 5 & $51-60$ & 1 \\
\hline & 6 & $61-70$ & 3 \\
\hline & 7 & $71-80$ & 1 \\
\hline & 8 & $81-90$ & - \\
\hline & Total & 17 \\
\hline
\end{tabular}

Clinical features in Acute cholecystitis

\begin{tabular}{|l|l|l|}
\hline Clinical features & No. of Patients & Percentage \\
\hline Pain Abdomen & 17 & $100 \%$ \\
\hline Vomitings & 15 & $88 \%$ \\
\hline Fever & 14 & $82 \%$ \\
\hline Jaundice & 6 & $35 \%$ \\
\hline Tenderness in Right & 17 & $100 \%$ \\
\hline hypochondrium & & \\
\hline Tachycardia & 12 & $71 \%$ \\
\hline Murphy's sign & 5 & $29 \%$ \\
\hline
\end{tabular}

\begin{tabular}{|l|l|l|l|}
\hline \multicolumn{2}{|l|}{ Results of Intestinal Obstruction } & & \\
\hline S. No & Clinical Condition & No. of patients & Percentage \\
\hline 1 & Adhesions & 7 & 50 \\
\hline 2 & Obstructed Hernia & 3 & 21 \\
\hline 3 & Malignancy & 2 & 15 \\
\hline 4 & Volulus & 1 & 7 \\
\hline 5 & Mesenteric Ischemia & 1 & 7 \\
\hline & Total & 14 & 100 \\
\hline
\end{tabular}

Out of 14 cases of intestinal obstruction, the commonest cause was Adhesions (7) constituting 50\%.

\begin{tabular}{|l|l|l|}
\hline Hernia Causing Obstruction & Type of Hernia & No. of Patients \\
\hline S. No & Incisiona Hernia & 2 \\
\hline 1 & Epigastric Hernia & 1 \\
\hline 2 & Total & 3 \\
\hline & \\
\hline
\end{tabular}




\begin{tabular}{|c|c|}
\hline Age Incidence of & \\
\hline Age & No. of Patients \\
\hline $11-20$ & - \\
\hline $21-30$ & - \\
\hline $31-40$ & 2 \\
\hline $41-50$ & 3 \\
\hline $51-60$ & 3 \\
\hline $61-70$ & 4 \\
\hline $71-80$ & - \\
\hline $81-90$ & 2 \\
\hline Total & 14 \\
\hline
\end{tabular}

\begin{tabular}{|l|l|l|l|}
\hline \multicolumn{3}{|c|}{ Signs and Symptoms of Intestinal Obstruction } & \\
\hline S. No & Clinical feature & No. of Patients & Percentage \\
\hline 1 & Abdominal Pain & 14 & 100 \\
\hline 2 & Vomitings & 13 & 92.8 \\
\hline 3 & Diarrhoea & 1 & 7 \\
\hline 4 & Constipation & 13 & 92.8 \\
\hline 5 & Previous Surgical Scar & 7 & 50 \\
\hline 6 & Rigidity & 4 & 28.6 \\
\hline 7 & Tenderness & 14 & 100 \\
\hline
\end{tabular}

Results for Gynaecological Causes Different gynaecological causes

\begin{tabular}{|l|l|l|l|}
\hline S.no & Causes & No.of.cases & \% \\
\hline 1 & Haemorrhagic cyst & 3 & 37.5 \\
\hline 2 & Twisted ovarian cyst & 2 & 25 \\
\hline 3 & Ruptured ectopic pregnancy & 2 & 25 \\
\hline 4 & Pelvic Inflammatory Disease & 1 & 12.5 \\
\hline & Total & $\mathbf{8}$ & $\mathbf{1 0 0}$ \\
\hline Results of Acute Pancreatitis & & \\
\hline Age incidence of Pancreatitis & & \\
\hline Age Group & No. of Patients \\
\hline $11-20$ & 2 & \\
\hline $21-30$ & 2 & \\
\hline $31-40$ & 2 & \\
\hline $41-50$ & 4 & \\
\hline $51-60$ & - & \\
\hline $61-70$ & - & \\
\hline $71-80$ & 1 & \\
\hline $81-90$ & - & \\
\hline Total & 11 \\
\hline
\end{tabular}

Etiology of Pancreatitis

\begin{tabular}{|l|l|l|l|}
\hline S.no & Causative factor & No. of Cases & Percentage \\
\hline 1 & Idiopathic & 7 & $64 \%$ \\
\hline 2 & Gall stone induced & 2 & $18 \%$ \\
\hline 3 & Neoplasia & 1 & $9 \%$ \\
\hline 4 & Post operative & 1 & $9 \%$ \\
\hline 5 & Alcohol & 0 & NIL \\
\hline
\end{tabular}

\begin{tabular}{|l|l|l|l|}
\hline \multicolumn{2}{|c|}{ Signs and Symptoms of Pancreatitis } & & \\
\hline S. No & Clinical Features & $\begin{array}{l}\text { No. of } \\
\text { Patients }\end{array}$ & Percentage \\
\hline 1 & Abdominal Pain & 11 & 100 \\
\hline 2 & Vomitings & 9 & 81.8 \\
\hline 3 & Diarrhoea & - & - \\
\hline 4 & Constipation & 7 & 63.6 \\
\hline 5 & Rigidity & 3 & 27.2 \\
\hline 6 & Tenderness & 11 & 100 \\
\hline
\end{tabular}

\begin{tabular}{|l|l|l|l|l|}
\hline \multicolumn{2}{|l|}{ Other Conditions } & & \\
\hline & S. No & & Causes & No. of Patients \\
\hline & 1 & & Acute Gastritis & 4 \\
\cline { 2 - 4 } & 2 & & Ulcerative Colitis & 1 \\
\hline & & Total & $\mathbf{5}$ \\
\hline
\end{tabular}




\section{Discussion}

Totally 100 cases were studied. Acute abdomen of traumatic origin was not included in this study to ensure correct diagnosis. The leading abdominal condition was Acute appendicitis accounting for $23 \%$ of cases studied, of which appendicectomy was done in 21 cases followed by urological causes like renal colic, ureteric colic, U.T.I e.t.c.., constituting $22 \%$ of total cases studied. The third common cause was Acute cholecystitis constituting $17 \%$ of total cases studied. The fourth common cause was Intestinal obstruction constituting $14 \%$ of total cases. Among these $14 \%$ of cases, majority of cases were due to adhesions. Gynaecological cases also included in the study like ruptured corneal pregnancy, twisted ovarian cyst, ectopic pregnancy e.t.c., constituting $7 \%$ of total cases studied. Other causes of abdomen like acute pancreatitis , acute gastritis , perforated appendix , ulcerative colitis was also included in the study which accounting for about $18 \%$ of total no.of.cases studied.

\section{Acute appendicitis}

Acute appendicitis is an important cause of acute abdominal pain. The incidence of appendicitis in all age groups is $7 \%$. The incidence of appendicitis in women is $6.7 \%$. Appendicitis is most commonly seen in subjects aged 10-30 years ${ }^{[4]}$. In present study maximum incidence of appendix is seen in the age group between 21-30 years. The median age for appendicitis in present study was 30.8 years The diagnosis of acute appendicitis is made by history and clinical findings. Although it can vary with age and sex; correct diagnosis can be made in $70 \%-80 \%$ of patients via history, physical examination and laboratory findings ${ }^{[5-7]}$. Diagnostic accuracy decreases in WORA ${ }^{[8]}$. Laboratory findings and radiological examination can support the diagnosis of appendicitis, but can never rule it out. The symptoms of acute appendicitis generally follow a certain sequence and include periumbilical pain (visceral, unlocalized), anorexia, nausea and/or vomiting, right lower quadrant abdominal pain and tenderness, hyperpyrexia,and leukocytosis. These symptoms may not be present at the same time. Physical findings suggesting appendicitis are McBurney tenderness, rebound tenderness, Muscle guarding, Abdominal rigidity, Mass in right iliac fossa, fullness and tenderness in the pelvis during digital rectal examination.McBurnys point tenderness is the most common physical examination finding of appendicitis in present study.

The main symptoms of acute appendicitis are frequently periumbilical pain preceded by anorexia and nausea. Vomiting is generally seen later. The pain generally switches to the right lower abdominal quadrant $8 \mathrm{~h}$ after the initial pain ${ }^{[9]}$. Although the clinical presentation of periumbilical pain migrating to the right lower abdominal quadrant is classically associated with acute appendicitis, the presentation is rarely typical and the diagnosis cannot always be based on medical history and physical examination alone. Classical clinical findings of appendicitis are observed in only $60 \%$ of patients with acute appendicitis, whereas $20 \%-33 \%$ display atypical clinical and laboratory findings ${ }^{[9]}$. Regardless of the technological advances in the preoperative diagnosis of acute appendicitis, the correct diagnosis can only be made in $76 \%-92 \%$ of cases ${ }^{[10,11]}$. On the other hand, $6 \%$ $25 \%$ of operations for acute appendicitis reveal normal appendix and this number can reach $30 \%-40 \%$ in WORA $^{[12-16]}$.

\section{Age incidence}

The present study shows maximum incidence of appendix shows in the age group between 21-30 years. The median age for appendicitis in present study was 30.8 years

\section{Clinical features}

In the present study all the patients had abdominal pain with right lower abdominal region and Mcburneys point tenderness as the first sign on physical examination, out of 23 cases of appendicitis $87 \%$ patients have vomitings and fever present $78 \%$ of patients which is comparable with study done by Hatipoglu S et al. ${ }^{[17]}$

\begin{tabular}{|l|l|l|}
\hline Clinical Features & Sinan hatipoglu et al. ${ }^{[17]}$ & Present study $^{[7]}$ \\
\hline Abdominal pain & $100 \%$ & $100 \%$ \\
\hline Vomiting & $65 \%$ & $87 \%$ \\
\hline Fever & $68 \%$ & $78 \%$ \\
\hline RIF tenderness & $100 \%$ & $100 \%$ \\
\hline Rebound tenderness & $100 \%$ & $65 \%$ \\
\hline
\end{tabular}

In present study out of 23 cases of appendicitis 18 patients had Leuckocytosis of which 10 patients had raised neutrophil count. 19 patients (83\%) on ultrasonography of abdomen and pelvis were confirmed as acute appendicitis In present study out of 23 cases, most of the cases were treated surgically which included laparoscopic appendicectomy and open appendicectomy. Out of 23 cases laparoscopic appendicectomy was done in 4 cases and open appendicectomy was done in 18 cases. Mortality is nil in present study of appendicitis. 


\section{Urological causes}

Urological causes was the $2^{\text {nd }}$ most common cause of acute abdomen in present study. Among 100 cases studied, $22 \%$ cases were due to urological causes. The urological causes in present study included UTI, pyelonephritis, renal colic and ureteric colic.

\section{Etiology}

Among 22 cases of urological causes, $23 \%$ cases were due to pyelonephritis, $18 \%$ cases were due to renal colic. Ureteric colic constitutes $27 \%$ of the cases and majority of the urological causes were due to urinary tract infections which comprises $32 \%$ of cases. The age spectrum was in between age groups 21 years and 70 years. The study showed the peak incidence is in the age group 21-40 years which comprises $72.7 \%$. Pain from the urogenital tract is usually triggered by sudden obstruction of urinary flow or by inflammation.

Urinary tract infections (UTIs) are one of the most common bacterial infections seen in primary care, second only to infections of the respiratory tract ${ }^{[18]}$. In the women, $25-30 \%$ of women between 20-40 years of age will get UTIs ${ }^{[19]}$. Women are particularly at risk of developing UTIs because of their short urethra, and certain behavioral factors which include delay in micturition, sexual activity and the use of diaphragms and spermicides which promote colonization of the periurethral area with coliform bacteria. Infection in women most often results from perineal or periurethral bacteria that enter the urethra and ascend into the bladder, often in association with sexual activity, or due to mechanical instrumentation such as catheterization ${ }^{[20]}$. Rates of infection are high in postmenopausal women because of bladder or uterine prolapse causing incomplete bladder emptying; loss of estrogen with attendant changes in vaginal flora (notably, loss of lactobacilli), which allows periurethral colonization with gramnegative aerobes, such as Escherichia coli. UTIs were the cause of acute abdominal pain in $7 \%$ of cases in present study group and was the most common cause of acute abdominal pain among urological causes.

Renal Colic: Renal pain is caused by acute stretching of the renal capsule and is perceived in the costovertebral angle lateral to the erector spinae muscle. Pain may be associated with gastrointestinal symptoms due to autonomic reflexes, this may obscure correct diagnosis. Renal colic was seen in $4 \%$ of cases in present study.

Ureteric Colic: Ureteral pain is triggered by a sudden obstruction of the ureteral lumen, this causes strain and hyperperistalsis of the ureter. The pain is usually undulating (renal colic). Obstruction of the proximal ureter is perceived as renal pain in the costovertebral angle. Pain caused by the middle ureter is projecting into the lower abdomen and to the scrotum or labia. Diseases of the distal ureter additionally may cause urinary frequency and dysuria. Ureteric colic was seen in $6 \%$ of cases in present study group.

Pyelonephritis is an inflammation of the renal parenchyma, calyces, and renal pelvis. It is commonly caused by bacterial infection that ascends up the urinary tract or spread through the bloodstream to the kidneys. Pyelonephritis presents with fever, painful micturition, abdominal pain radiating to the back, nausea, and tenderness at the costovertebral angle on the affected side. Pyelonephritis can progress to urosepsis leading to septic shock. In present study, $5 \%$ of cases were diagnosed as having acute pyelonephritis.

The following table compares the etiology of Urological causes in females for acute abdominal pain of present study with a study done by Biswajith barai et al. ${ }^{[21]}$

\section{Comparision of Urological causes of Acute abdomen}

\begin{tabular}{|l|l|l|l|l|}
\hline Study group & UTI & Ureteric Colic & Pyelonephritis & Renal Colic \\
\hline Biswajit barai et & $7 \%$ & $4 \%$ & $3 \%$ & $5 \%$ \\
\hline al.(2016) ${ }^{[21]}$ & & & & \\
\hline Present study & $7 \%$ & $6 \%$ & $5 \%$ & $4 \%$ \\
\hline
\end{tabular}

\section{Clinical Features}

In the present clinical study, pain abdomen was present in all cases and $68 \%$ of cases were presented with fever. Where-as $77 \%$ patients were presented with renal angle tenderness.

\section{Diagnosis}

A diagnosis of urological cause for acute abdominal pain can be arrived at with help of clinical history, physical examination findings, Labratory investigations - Complete Urine analysis, Renal function tests, Hemogram etc. and radiolgical investigations namely X ray KUB, Ultrasonography and CT scan where needed.

Almost majority of the cases were treated conservatively. Only $14 \%$ cases were treated surgically. In two cases of ureteric colic DJ stent was done and in one case of ureteric colic ureteroscopic lithotripsy was done. Mortality was nil in this group of study. 


\section{Acute Cholecystitis}

Acute Cholecystitis is the third most common cause for patients presenting with acute abdomina pain in present study. It is the inflammation of the gallbladder that occurs most commonly because of an obstruction of the cystic duct by gallstones arising from the gallbladder (cholelithiasis).

Out of 100 cases in our clinical study incidence of acute cholecystitis is $14 \%$. In study conducted by Biswajit barai et al. ${ }^{[21]}$ (2016) incidence was $13 \%$, which is comparable to present study. In Samir Ray et al. ${ }^{[22]}$ series incidence was $9 \%$.

\section{Age Incidence}

The age spectrum in our clinical study includes patients from 18 years to 80 years of age. The peak incidence of cholecystitis in present study was seen in the age group of 41-50 years (29\%), which is in accordance with the standard norms.

\section{Clinical features}

The most common presenting symptom of acute cholecystitis is upper abdominal pain. Frequently, the pain begins in the epigastric region and then localizes to the right upper quadrant (RUQ). Although the pain may initially be described as colicky, it becomes constant in virtually all cases. Nausea and vomiting are generally present, and patients may report fever.

In present study Pain in upper abdomen and tenderness in right hypochondrium were present in all the patients. Other acute symptoms like vomitings and fever were present in $88 \%$ and $82 \%$ of the patients respectively. Jaundice was limited to only $35 \%$ of the patients. Murphy's sign was seen in only $29 \%$ of the patients with acute cholecystitis in present study group.

Patients with acalculous cholecystitis may present similarly to patients with calculous cholecystitis, but acalculous cholecystitis frequently occurs suddenly in severely ill patients without a prior history of biliary colic. Often, patients with acalculous cholecystitis may present with fever and sepsis alone, without history or physical examination findings consistent with acute cholecystitis. In present study we didnot come across any case of acalclous cholecystitis.

Most patients with acute cholecystitis describe a history of biliary pain. Some patients may have documented gallstones. Acalculous biliary colic also occurs, most commonly in young to middle-aged females. The presentation is almost identical to

calculous biliary colic with the exception of reference range laboratory values and no findings of cholelithiasis on ultrasound. Cholecystitis is differentiated from biliary colic by the persistence of constant severe pain for more than 6 hours.

\section{Complications}

Bacterial proliferation within the obstructed gallbladder results in empyema of the organ. Patients with empyema may have a toxic reaction and may have more marked fever and leukocytosis. ${ }^{[23,24]}$ The presence of empyema frequently requires conversion from laparoscopic to open cholecystectomy. ${ }^{[25]}$ In present study one patient with acute cholecystitis operated for acute symptoms refractory to conservative management was diagnosed as empyema gallbladder which was converted from laparoscopic to open cholecystectomy.

In rare instances, a large gallstone may erode through the gallbladder wall into an adjacent viscus, usually the duodenum. Subsequently, the stone may become impacted in the terminal ileum or in the duodenal bulb and/or pylorus, causing gallstone ileus.

Emphysematous cholecystitis occurs in approximately $1 \%$ of cases and is noted by the presence of gas in the gallbladder wall from the invasion of gas-producing organisms, such as Escherichia coli, Clostridia perfringens, and Klebsiella species. This complication is more common in patients with diabetes, has a male predominance, and is acalculous in $28 \%$ of cases. Because of a high incidence of gangrene and perforation, emergency cholecystectomy is recommended. Perforation occurs in up to $15 \%$ of patients. ${ }^{[24,26]}$. We did not come across any case of emphysematos cholecystitis in present study group.Other complications includes sepsis and pancreatitis ${ }^{[27]}$. We came across 2 cases of gall stone induced acute pancreatitis which are discussed under pancreatitis heading.

\section{Diagnosis}

Diagnosis of acute cholecystitis is made on the basis of clinical features and is supported by results of ultrasound scanning.

All the patients except one among the 17 patients diagnosed with acute cholecystitis were managed conservatively and later interval cholecystectomy was done laparoscopically. One case diagnosed as empyema gallbladder was operated and converted to open cholecystectomy as already mentioned above. 


\section{Intestinal obstruction}

Intestinal obstruction is the fourth most common cause of acute abdomen in present study. It is defined as obstruction in forward propulsion of the contents of the intestine either due to dynamic, adynamic or pseudoobstruction. It is predisposed by varying underlying anomalies and diseases, which are difficult to define preoperatively. Intestinal obstruction of either the small or large bowel continues to be a major cause of morbidity and mortality. Mode of presentation is same, but underlying cause may vary. In earlier part of the century mortality and morbidity was very high. Now with better understanding of pathophysiology, improvement in radiological techniques of diagnosis and high degree of refinement in correction of fluid and electrolyte imbalance, introduction of antibiotics for effective bacteriological control, introduction of techniques in gastrointestinal decompression, new surgical principles, like on table lavage and resection and primary anastomosis replacing staged procedures and number of days in hospital stay, improvement in field of anaesthesia, has all contributed to lower the morbidity and mortality.

In our clinical study incidence of intestinal obstruction was $14 \%$ of total study group. It is compared with other studies i.e., in Naveen $\mathbf{N}$ et al. ${ }^{[28]}$ series incidence was $3 \%$ of total study group.

\section{Age Incidence}

Intestinal obstruction although occurs in all age groups, the age spectrum in our clinical study was between age group of 31 years to 90 years. The study shows peak incidence is in the age group of 41-60 years of $43 \%$ and 61-70 years of 29\% which is comparable with previous study groups Deepak thampi et al., Naveen N et al series.

\begin{tabular}{|l|l|l|l|}
\hline Age group & Deepak thampi et al. ${ }^{[29]}$ & Naveen N et al. ${ }^{[28]}$ & Present study \\
\hline $11-20$ & $7 \%$ & $16 \%$ & - \\
\hline $21-30$ & $21 \%$ & $8 \%$ & - \\
\hline $31-40$ & $21 \%$ & $16 \%$ & $14 \%$ \\
\hline $41-50$ & $7 \%$ & $16 \%$ & $21.5 \%$ \\
\hline $51-60$ & $14 \%$ & $25 \%$ & $21.5 \%$ \\
\hline $61-70$ & $21 \%$ & $12 \%$ & $29 \%$ \\
\hline $71-80$ & $7 \%$ & & - \\
\hline $81-90$ & - & - & $14 \%$ \\
\hline
\end{tabular}

Age incidence of intestinal obstruction in females in different studies

\section{Etiology}

The commonest cause was found to be Adhesions followed by obstructed hernia, malignancies, volvulus and mesenteric ischemia. Although in developing countries like India, the commonest cause used to be obstructed hernia, but in our clinical study the commonest cause was Adhesions followed by obstructed hernia which includes epigastric and incisional hernia as second cause. The decrease in the incidence of obstructed hernias indicates a changing trend towards early operation before hernia gets complicated.

In the present study of 14 cases of intestinal obstruction, $50 \%$ cases were due to adhesions and $21 \%$ cases were due to obstructed hernia which includes epigastric and incisional tye of hernias, $15 \%$ were due to Malignancies, $7 \%$ were due to mesenteric ischemia and $7 \%$ were due to volvulus. These were compared with other studies in the following table-

\begin{tabular}{|l|l|l|l|}
\hline Cause & Sabitha P et al. ${ }^{[31]}$ & Kamalin viji et al. $^{[32]}$ & Present study \\
\hline Adhesion & $21 \%$ & $37.5 \%$ & $50 \%$ \\
\hline Obstructed hernia & $21 \%$ & $31 \%$ & $21 \%$ \\
\hline Abdominal TB & $10 \%$ & $3 \%$ & - \\
\hline Volvulus & $12 \%$ & $6 \%$ & $7 \%$ \\
\hline Malignancy & $20 \%$ & $22 \%$ & $15 \%$ \\
\hline Mesenteric ischemia & $5 \%$ & & $7 \%$ \\
\hline
\end{tabular}

\section{Comparision of causes of Intestinal obstruction in females in different studies}

The clinical features of intestinal obstruction pain abdomen, tenderness, vomiting were present in majority of cases. But vomitings, diarrhoea, constipation were not present in all cases. Pain abdomen and tenderness was present in $100 \%$ cases in present study, where as vomitings was present in 92.8 cases and constipation was present in $92 \%$ of the cases.

\section{Laboratory investigations}

Among the total study population $29 \%$ of the cases were having anemia, many cases have shown elevated leuckocyte count and otherwise the basic haematological investigations did not yield much statistical significance. 


\section{Imaging studies}

The erect abdomen $\mathrm{x}$ ray helps us in the diagnosis of intestinal obstruction as well as in differentiating the small bowel with large bowel obstruction. Multiple air fluid levels can be seen in small bowel intestinal obstruction where as only gas shadows are seen in large bowel obstruction until the ileo-caecal valve is competent. In the present study of the 14 cases $75 \%$ of x rays show multiple air fluid levels, remaining cases with diated bowel shadows. Contrast study with barium enema may help to locate the obstruction in the colon, but in present study it was not done.

Conservative management was successful in half of the cases. Remaining cases were treated surgically according to their diagnosis. Most of the cases were due to adhesions(50\%), due to hernia(21\%), volvulus(7\%).

The surgical management for the present study group includes laparoscopic adhesiolysis for 2 cases of adhesions, exploratory laparotomy \& resection \& anastomosis for 2 cases of malignancy and exploratory laparotomy \& adhesiolysis \& hernioplasty for one case. Where as for obstructed epigastric hernia, release of constricting agents and hernioplasty was done. For volvulus i.e., caecal volvulus, hemicolectomy with ileotransverse anastomosis was done.

\section{Acute Pancreatitis}

Acute Pancreatitis was also one of the most common cause of acute abdominal pain in females during the study period. Pancreatitis simply means inflammation of the pancreas.

In present study out of 100 cases, Acute pancreatitis was diagnosed as the cause of acute abdominal pain in $11 \%$ of the cases. In a study done by Biswajit barai et al. The incidence of acute pancreatitis among female cases of acute abdomen was $10 \%$. In a similar study done by Samir ray et al. ${ }^{[22]}$ Incidence was $7 \%$ among females.

\section{Age Incidence}

The present study shows maximum incidence of pancreatitis shown in the age group between 41-50 years. The spectrum of age is in between 15-70 years.

EtiologyCauses of acute pancreatitis include alcohol abuse and gallstones (about 35\%-45\% for each); while the remaining 10\%-20\% are caused by medications, chemical exposures, trauma, hereditary diseases, infections, surgical procedures, and Hyperlipidemias and genetic abnormalities with pancreas or intestine In present study most common cause for acute pancreatitis was Idiopathic(64\%), followed by gall stone induced pancreatitis(18\%), Post operative and neoplasia (9\% each).

The follwing table compares the etiolgical factors for acute pancreatitis in female patients in present study with that of A P Corfield et al. ${ }^{[33]}$

Comparision of etiology for Acute pancreatitis in females

\begin{tabular}{|l|l|l|}
\hline Causative factor & A P Corfield et al. ${ }^{[33]}$ & Present study \\
\hline Idiopathic & $23 \%$ & $64 \%$ \\
\hline Gall stone induced & $58 \%$ & $18 \%$ \\
\hline Neoplasia & $1 \%$ & $9 \%$ \\
\hline Post operative & $31 \%$ & $9 \%$ \\
\hline Alcohol & $2 \%$ & NIL \\
\hline
\end{tabular}

\section{Clinical Features}

Symptoms of acute pancreatitis most commonly begins with abdominal pain in the upper abdomen and abdominal pain may increase after eating or lying flat on the back. Other symptoms may include nausea, fever, tachycardia, and dehydration. Severe acute pancreatitis symptoms and signs may show skin discoloration around the umbilicus or the side of the body between the ribs and hip (flank), or small erythematous skin nodules.

In the present study out of 11 cases of pancreatitis all patients have abdominal pain and tenderness. $81.8 \%$ patients were having vomitings, whereas constipation is seen in $63.6 \%$ of patients. $27.2 \%$ of patients were noted rigidity.

Necrotizing pancreatitis is a severe form of acute pancreatitis characterized by necrosis in and around the pancreas. In present study group, 2 cases were found to have necrotizing pancreatitis which were then referred to higher centres for further management.

\section{Diagnosis}

Serum Amylase is sensitive for pancreatitis but has poor specificity as it is elevated in many other conditions, and hence it alone cannot be taken into consideration for diagnosis of acute pancreatitis. It is supported by serum lipase levels and findings on ultrasonography in combination with clinical history and 
physical examination to arrive at the diagnosis of acute pancreatitis. Other investigations like Liver function tests, Serum electrolytes, Lipid profile etc.. can help in identifying the causative factor. Other routine investigations are done to evaluate the patient.

All cases were treated conservatively. Mortality rate was nil in this study group.

\section{Gynaecological Causes}

In present study gynaecological conditions were also included. Out of 100 cases studied, 8 cases were of gynaecological causes. These included twisted ovarian cyst, ruptured ectopic pregnancy, PID and haemorrhagic cysts. The cases in present study were between age group 21-60 years. Almost all cases presented with pain abdomen and ruptured ectopic pregnancy is presented with bleeding $\mathrm{p} / \mathrm{v}$. Abdominal distension was seen in twisted ovarian cyst.

Pelvic pain during the ovulatory cycle may be observed due to a small amount of blood which drains from the ruptured ovarian follicle into the peritoneal cavity during ovulation. This pain is mild-to-moderate and limited, and hemoperitoneum is seldom observed with normal hemostatic parameters. Thus, there is generally no need for surgical intervention in these circumstances ${ }^{[34]}$.

Corpus hemorrhagicum cysts are one of the most common ovarian cysts. They are formed as a result of hemorrhage into the follicle cyst or corpus luteum cyst in the ovaries during the ovulation period ${ }^{[35-39]}$. The clinical signs and symptoms are variable and include patients who are asymptomatic or patients with symptoms of acute abdomen ${ }^{[35]}$. These cysts are commonly seen in a single ovary, and are rarely observed bilaterally. They are more frequently seen in patients undergoing ovulation therapy for pregnancy. They are also seen in patients with bleeding disorders and coagulation problems or those on anticoagulant treatment. They may require surgery due to intraabdominal hemorrhage as a result of rupture or torsion ${ }^{[37-39]}$. In general, bleeding can be stopped by excision of the cyst, however, sometimes the ovary needs to be removed. We observed corpus hemorrhagicum cyst rupture in $\mathbf{3 \%}$ of the patients in present study. All of these patients had stable hemodynamics and did not require blood transfusion. The patients were in their active reproductive period, which is in accordance with the literature ${ }^{[40]}$.

Ovarian cyst rupture occurs due to benign or malignant cystic lesions of the ovaries. Cyst excision is a convenient treatment choice in young patients. It is important not to remove the whole ovary. Oophorectomy can be performed in older patients. It should be taken into consideration, that young patients with ovarian germ cell tumors may be associated with acute abdomen ${ }^{[4]}$.Hemodynamic parameters in patients with ovarian cyst rupture may be impaired due to blood los ${ }^{[1,42]}$.Suturing, cauterization of the bleeding site or cyst excision can be performed for ovarian cyst rupture ${ }^{[42]}$. Hemodynamic parameters in these patients were stable and there was no need for blood transfusion.

Adnexal torsion is a well-known, but difficult to diagnose cause of acute abdomen due to variable clinical causes and symptoms, and involves the tuba folding up on itself. Clinical findings are similar to those of acute appendicitis ${ }^{[43,44,45]}$. Ovarian torsion is observed in $2 \%-3 \%$ of patients undergoing surgery with a diagnosis of acute appendicitis ${ }^{[43-47]}$. Ovarian torsion was observed in $\mathbf{2 \%}$ of patients in the present study which is correlated with Hatipoglu S et al. ${ }^{[17]}$ study. It is observed 3-fold more frequently on the right compared with the left side ${ }^{[42,43]}$. It is relatively easy to differentiate ovarian torsion from other causes of acute abdomen via ultrasonography during the early period ${ }^{[48,49]}$. Adnexal torsions without symptoms are dangerous and caution should be taken in these cases. Removal of the adnexae and eventual infertility risk is likely. Excision of necrotic tissue is suggested before detorsion, due to the risk of pulmonary thromboembolism $(0.2 \%)$, if vividness of the ovary is lost and a gangrene demarcation line has already formed ${ }^{[50,51]}$. In present study, we observed one patient in whom the ovary had lost its normal structure and had a necrotic appearance, and oophorectomy was performed before detorsion. Another three patients with ovarian torsion underwent detorsion and ovarian fixation. Cohen et $\boldsymbol{a l}^{[52]}$ reported that torsioned, ischemic and hemorrhagic adnexa can be detorsioned laparoscopically with minimal morbidity and complete recovery of ovarian function.

Usually cases of ruptured ectopic pregnancy present with complaints of Pain abdomen following period of amenorrhoea with associated bleeding per vaginum. The diagnosis of ectopic pregnancy is generally quick and easy following the measurement of $\beta$-hCG. Ruptured ectopic pregnancy was observed in $\mathbf{2 \%}$ patients in present study which is correlated with Dr. Biswajit barai et al. study .

Pelvic inflammatory disease (PID) is an infection of the upper part of the female reproductive system. It is often asymptomatic. Signs and symptoms, when present may include lower abdominal pain, vaginal discharge, fever, burning with urination, dysperunia, or irregular menstruation. Untreated PID can result in long term complications including infertility, ectopic pregnancy, chronic pelvic pain, and cancer. In present study PID was seen in $1 \%$ of cases studied. 
In present study out of 8 cases, 5 cases were treated conservatively. Only 3 cases were treated surgically. In case of left twisted ovarian cyst, salpingo-oophorectomy was done. Whereas in cases of ruptured ectopic pregnancy, emergency laparotomy was done. Mortality was nil in this group of study.

\section{Other Causes}

Acute Gastritis is inflammation or irritation of the lining of the stomach. Gastritis has many causes such as alcohol use, intake of spicy food, Infective, NSAID induced, Autoimmune causes(atrophic gastritis).

Foods that may cause gastritis can differ from person to person, but in general, foods that can cause gastritis include beverages that contain alcohol or caffeine, spicy foods, foods that contain chocolate, or foods high in fat. Symptoms of gastritis are indigestion (burning pain in upper abdomen), nausea or vomiting, excessive belching, occasionally distension of abdomen in severe cases. In present study of 100 female patients acute gastritis resulted in acute pain abdomen in $\mathbf{4 \%}$ of the cases.Diagnosis is by Upper GI endoscopy and managed conservatively with PPIs and Anti H.pylori regimen

Ulcerative Colitis accounted for $1 \%$ of cases of acute abdomen in the study group during the study period. Ulcerative colitis is charecterised by non specific inflammation which almost always starts with rectum and ascends up to involve colon. Etiology of UC is unknown. Well known and accepted hypothesis include Immune system dysfunction to normal gut bacteria and Environmental factors explained by hygiene hypothesis. Most common symptoms are episodes of pain in the abdomen assosciated with bloody diarrhoea. Diagnosis is by Colonoscopy and managed conservatively with immunomodulators and steroids.

\section{Hollow viscus perforation}

Non traumatic hollow viscus perforation is one of the commonest surgical emergencies requiring hospitalisation and early management. Peptic ulcer disease which was once so common 3 to 4 decades ago has now drastically decreased in incidence due to advent of PPIs and Antibiotics. In present study one case presented with perforation secondary to caecal volvulus..Diagnosis was confirmed by CT scan. Right hemicolectomy and ileo-transverse colonic anastamosis was done. Other causes of Acute abdomen in females which we have not come across in present study include conditions like Liver abscess is relatively rare in females. It is almost 9 times more common in males when compared to females as per a study done by Shyam mathur et al. ${ }^{[53]}$

It has been described since the time of Hippocrates, with the first published review by Bright appearing in 1936. The development of newer radiological techniques and improvement in microbiological identification and advancement of drainage techniques as well as improved supportive care have decreased mortality rates to 5 to $30 \%$. Yet the prevalence of liver abscess has remained relatively unchanged

Mesenteric lymphadenitis more common in pediatric age group. The enlargement of mesenteric lymph nodes frequently causes abdominal pain in children, being an indication for laboratory investigations. Vomiting and fever are the other most common symptoms in these patients. Ultrasonographic examination usually shows enlargement of lymph nodes, sometimes in conglomerates, with tendency to invagination. Acute diarrhea and respiratory tract infection are the most frequent reasons of the enlargement of abdominal lymph nodes. In about $20 \%$ of the children primary mesenteric lymphadenopathy is diagnosed.

Abdominal aortic aneurysm (AAA) is a localized enlargement of the abdominal aorta such that the diameter is greater than $3 \mathrm{~cm}$ or more than $50 \%$ larger than normal diameter. They are usually asymptomatic except when ruptured. AAAs occur most commonly in men over 50 years old, and among those with a family history. Occasionally, pain in the abdomen, back, or lower limbs may occur. Rupture usually results in massive internal hemorrhage, and is a surgical emergency.

\section{Summary And Conclusions}

This Prospective study was conducted to study Non traumatic causes of acute abdomen in females over a duration of 2 years and 100 consecutive cases were studied during that time period.

Informed Consent was taken from all the patients that were included in the study.

Data was obtained by meticulous history taking, Clinical examination of the patient and relevent investigations. Data thus obtained was recorded in case recording form and analysed to arrive at the following conclusions- Spectrum of diseases in females presenting with non traumatic acute abdominal pain in this study were Acute appendicitis, Urological causes like UTIs, Renal colic etc. followed by Acute Cholecystitis, Intestinal obstruction followed by other causes.

Of which Acute Appendicitis is the most common cause of acute abdominal pain of non traumatic origin in females presenting to surgeon. Acute appendicitis previously was and still remains to be the commonest cause of non traumatic acute abdominal pain and it requires early intervention either by means of open surgery or laparoscopic appendicectomy. 
Most Common age group in females that presented with Non traumatic Acute Abdomen was between 2130 years. Most Consistent symptom was Pain abdomen followed by vomiting Most consistent Clinical sign was Abdominal tenderness Most consistent Laboratory investigation was Leuckocytosis Imaging studies form a good supplement to the History taking and Physical examination, especially in cases that are difficult to arrive at a diagnosis. Patients were managed either conservatively or surgically depending on their diagnoses.

Mortality was nil in the study group.

\section{References}

[1]. Kamin RA, Nowicki TA, Courtney DS, Powers RD. Pearls and Pitfalls in the Emergency Department Evaluation of Abdominal Pain. Emerg Med Clin North Am 2003;21:61-72.

[2]. Levine MS, Bree RL, Foley WD, et al., for the Expert Panel on Gastrointestinal Imaging. American College of Radiology ACR Appropriateness Criteria. Left lower quadrant pain.2000 Jun;215 Suppl:167-71.

[3]. Bree RL, Blackmore CC, Foley WD, et al., for the Expert Panel on Gastrointestinal Imaging. American College of Radiology ACR Appropriateness Criteria. Right lower quadrant pain. 2000 Jun;215 Suppl:159-66.

[4]. Shelton T, McKinlay R, Schwartz RW. Acute appendicitis: current diagnosis and treatment. Curr Surg 2003; 60: 502-505

[5]. Howell JM, Eddy OL, Lukens TW, Thiessen ME, Weingart SD, Decker WW. Clinical policy: Critical issues in the evaluation and management of emergency department patients with suspected appendicitis. Ann Emerg Med 2010; 55: 71-116 6.Ebell MH. Diagnosis of appendicitis: part 1. History and physical examination. Am Fam Physician 2008; 77: 828-830

[6]. Humes DJ, Simpson J. Acute appendicitis. BMJ 2006; 333: 530-534

[7]. $\quad$ Old JL, Dusing RW, Yap W, Dirks J. Imaging for suspected appendicitis. Am Fam Physician 2005; 71: 71-78

[8]. Ma KW, Chia NH, Yeung HW, Cheung MT. If not appendicitis, then what else can it be? A retrospective review of 1492 appendectomies. Hong Kong Med J 2010; 16: 12-17

[9]. Andersson RE, Hugander A, Ravn H, Offenbartl K, Ghazi SH, Nyström PO, Olaison G. Repeated clinical and laboratory examinations in patients with an equivocal diagnosis of appendicitis. World J Surg 2000; 24: 479-485.

[10]. Walker AR, Segal I. What causes appendicitis? J Clin Gastroenterol 1990; 12: 127-129

[11]. Paulson EK, Kalady MF, Pappas TN. Clinical practice. Suspected appendicitis. N Engl J Med 2003; 348: 236-242

[12]. Flum DR, Koepsell T. The clinical and economic correlates of misdiagnosed appendicitis: nationwide analysis. Arch Surg 2002; 37: 799-804

[13]. Hardin DM. Acute appendicitis: review and update. Am Fam Physician 1999; 60: 2027-2034

[14]. Hoffman D. Aids in the diagnosis of acute appendicitis. Br J Surg 1989; 74: 774-779

[15]. Singhal V, Jadhav V. Acute appendicitis: are we over diagnosing it? Ann R Coll Surg Engl 2007; 89: 766-769

[16]. Hatipoglu S, Hatipoglu F, Abdullayev R. Acute right lower abdominal pain in women of reproductive age: Clinical clues. World J Gastroenterol. 2014;20(14):4043-9.

[17]. Pushpalatha KS. Urinary tract infection and management. J Nighting Nursing Times 2008;4(5):28-32.

[18]. Wilma JP. Shafers Medical Surgical Nursing. 7th edition, B.I. Publications: New Delhi 2002:p.637-40.

[19]. Litza JA, Brill JR. Urinary tract infections. Prim Care 2010;37(3):491-507

[20]. Barai B, Mandal A, Chakroborty P, Bhattacharyya S, Bala S. Spectrum of Diseases in Patients with Non-Traumatic Acute Abdominal Pain Presenting to General Surgery Department in a Rural Tertiary Care Centre in West Bengal. International Journal of Science and Research. 2016;5(3):1244-48.

[21]. Ray S, Patel M, Parmar H. Management of acute abdomen: Study of 110 cases. IAIM. 2016;3(2):18-24

[22]. Gruber PJ, Silverman RA, Gottesfeld S, et al. Presence of fever and leukocytosis in acute cholecystitis. Ann Emerg Med. 1996 Sep. 28(3):273-7.

[23]. Nidimusili AJ, Alraies MC, Eisa N, Alraiyes AH, Shaheen K. Leukocytosis of unknown origin: gangrenous cholecystitis. Case Rep Med. 2013. 2013:418014. 25.Liolios A, Oropello JM, Benjamin E. Gastrointestinal complications in the intensive care unit. Clin Chest Med. 1999 Jun. 20(2):329-45,

[24]. Chiu HH, Chen CM, Mo LR. Emphysematous cholecystitis. Am J Surg. 2004 Sep. 188(3):325-6

[25]. Moscati RM. Cholelithiasis, cholecystitis, and pancreatitis. Emerg Med Clin North Am. 1996 Nov. 14(4):719-37.

[26]. Naveen N, Mukherjee A, Nataraj Y S, Linge gowda S N. A CLINICAL STUDY OF

[27]. INTESTINAL OBSTRUCTION AND ITS SURGICAL MANAGEMENT IN RURAL POPULATION. Jemds. 2013;2(21):3636-49.

[28]. Thampi D, Tukka VN, Bhalki N, Sreekantha, Remya, SSA. A clinical study of

[29]. surgical management of acute intestinal obstruction. Int J Res Health Sci 2014; 2(1):299-308

[30]. Naveen N, Mukherjee A, Nataraj Y S, Linge gowda S N. A CLINICAL STUDY OF

[31]. INTESTINAL OBSTRUCTION AND ITS SURGICAL MANAGEMENT IN RURAL POPULATION. Jemds. 2013;2(21):3636-49.

[32]. Sabitha P,Naga Muneiah S. A Clinical Study of Acute Intestinal Obstruction in a Teaching Hospital. International Journal of Research in Health Sciences. 2015;3(2):295-302.

[33]. Kamalin Viji G. A Prospective Clinical Study of Dynamic Intestinal Obstruction in A Tertiary Care Centre. Indian Journal of Applied Research. 2016;6(5):111-3.

[34]. Corfield A, Cooper M, Williamson R. Acte Pancreatitis: a lethal disease of increasing incidence. Gut. 1985;26:724-9.

[35]. LeMaire WJ. Mechanism of mammalian ovulation. Steroids 1989; 54: 455-469

[36]. Nemoto Y, Ishihara K, Sekiya T, Konishi H, Araki T. Ultrasonographic and clinical appearance of hemorrhagic ovarian cyst diagnosed by transvaginal scan. J Nippon Med Sch 2003; 70: 243-249

[37]. CLAMAN AD. Bleeding from the ovary: graafian follicle and corpus luteum. Can Med Assoc J 1957; 76: 1036-104065.Hoyt WF, Meigs JV. Rupture of the graffian follicle and corpus luteum. Surg Gynecol Obstet 1963; 62: 114-118

[38]. Hoyt WF, Meigs JV. Rupture of the graffian follicle and corpus luteum. Surg Gynecol Obstet 1963; 62: 114-118

[39]. Yoffe N, Bronshtein M, Brandes J, Blumenfeld Z. Hemorrhagic ovarian cyst detection by transvaginal sonography: the great imitator. Gynecol Endocrinol 1991; 5: 123-129

[40]. Bass IS, Haller JO, Friedman AP, Twersky J, Balsam D, Gottesman R. The sonographic appearance of the hemorrhagic ovarian cyst in adolescents. J Ultrasound Med 1984; 3: 509-513

[41]. Rapkin AJ. Pelvic pain and dismenorrea. In: Berek JS, Adashi EY, Hillard PA, editors: Novak’s gynecology, 13th ed. Pennsylvania: Lippincott Williams \& Wilkins, 2004: 399-403

[42]. Nakhgevany KB, Clarke LE. Acute appendicitis in women of childbearing age. Arch Surg 1986; 121: 1053-1055.

[43]. Evsen MS, Soydinc HE. Emergent gynecological operations: A report of 105 cases. J Clin Exp Invest 2010; 1: 12-15 
[44]. Burnett LS. Gynecologic causes of the acute abdomen. Surg Clin North Am 1988; 68: 385-398

[45]. Hibbard LT. Adnexal torsion. Am J Obstet Gynecol 1985; 152: 456-461

[46]. Nichols DH, Julian PJ. Torsion of the adnexa. Clin Obstet Gynecol 1985; 28: 375-380

[47]. Mage G, Canis M, Manhes H, Pouly JL, Bruhat MA. Laparoscopic management of adnexal torsion. A review of 35 cases. J Reprod Med 1989; 34: 520-524

[48]. van der Zee DC, van Seumeren IG, Bax KM, Rövekamp MH, ter Gunne AJ. Laparoscopic approach to surgical management of ovarian cysts in the newborn. J Pediatr Surg 1995; 30: 42-43

[49]. Tepper R, Zalel Y, Goldberger S, Cohen I, Markov S, Beyth Y. Diagnostic value of transvaginal color Doppler flow in ovarian torsion. Eur J Obstet Gynecol Reprod Biol 1996; 68: 115-118

[50]. Davis LG, Gerscovich EO, Anderson MW, Stading R. Ultrasound and Doppler in

[51]. the diagnosis of ovarian torsion. Eur J Radiol 1995; 20: 133-136

[52]. Kurzbart E, Mares AJ, Cohen Z, Mordehai J, Finaly R. Isolated torsion of the fallopian tube in premenarcheal girls. J Pediatr Surg 1994; 29: 1384-1385 51.Stenchever M, Droegemueller W, Herbst A, Mishell D. Benign gynecologic lesions. In: Comprehensive gynecology, 4th edn. St. Louis, MO: Mosby Publishing Company, 2001: 519-520

[53]. ohen SB, Oelsner G, Seidman DS, Admon D, Mashiach S, Goldenberg M. Laparoscopic detorsion allows sparing of the twisted ischemic adnexa. J Am Assoc Gynecol Laparosc 1999; 6: 139-143

[54]. Shyam Mathur, Gehlot S R, Mohta A, Bhargava N. Clinical Profile of Amoebic Liver Abscess. JIACM. 2002;3(4):367-73. 